\title{
El debido proceso y el derecho de defensa en el ámbito educativo
}

\author{
Due Process and the Right of Defense in the Education Field
}

\author{
Elizarda Vargas Morúa ${ }^{1}$ \\ Universidad Estatal a Distancia, Costa Rica
}

\begin{abstract}
Resumen. El presente trabajo se realiza con base en tres Recursos de Amparo en los cuales se analizó si hubo cumplimiento del Principio al Debido Proceso y el Derecho de defensa durante la tramitación de los procesos disciplinarios por violencia escolar en tres centros educativos. Adicionalmente, se enfatiza en diferenciar la violencia escolar en general del fenómeno del bullying. Todo estudiante investigado por alguna falta disciplinaria debe tener conocimiento preciso de los hechos por los que se le investiga, las posibles sanciones y además poder acceder a las pruebas en su contra, para luego ejercer su defensa apropiadamente. La imposición de sanciones, sin respetar el orden establecido en el Reglamento de Evaluación de los Aprendizajes, acarrea una violación al principio constitucional del debido proceso, según se puede constatar al revisar resoluciones dictadas por la Sala Constitucional de la Corte Suprema de Justicia de Costa Rica, como ocurrió en los casos en estudio. Además, la Sala rechazará cualquier recurso que pretenda dirimir un conflicto entre partes, porque su labor consiste en verificar que se hayan respetado los principios y los procedimientos dentro del proceso disciplinario llevado a cabo. La trascendencia del presente estudio consiste en que a través del análisis de casos concretos llevados a la Sala Constitucional se puede aprender de materia disciplinaria y evitar incurrir en errores que cometen los centros educativos durante la tramitación de procesos.
\end{abstract}

Palabras clave. Violencia escolar, Sala Constitucional, debido proceso, proceso disciplinario, Reglamento de Evaluación de los Aprendizajes.

\begin{abstract}
This work is made based on three writs of mandamus in which the fulfillment of the Due Process Principle and principle of defense were analyzed during disciplinary processes carried out at education centers. Furthermore, it emphasizes on differentiating regular school violence and bullying. Every student investigated for any disciplinary fault must have specific knowledge of the facts on which he/she is investigated, possible sanctions, and must also have access evidence against him/her, so he/she can then defend him/herself accordingly . The application of sanctions without respecting the order set forth in the the Regulation for Learning Assessment breaches the constitutional principle of Due Process, as can be determined by reviewing resolutions issued by the Constitutional Court of Costa Rica, such as the cases under study. On the other hand, the Constitutional Chamber will reject any application seeking to resolve a conflict between parties, as its job is to verify the compliance of principles and procedures within the disciplinary process being carried out. The importance of this study is that we can learn about disciplinary matters through the analysis of specific cases brought to the Constitutional Court and prevent schools from making mistakes during the judicial proceedings.
\end{abstract}

Keywords. School violence, Constitutional Court, due process, disciplinary process, Regulation for Learning Assessment

${ }^{1}$ Elizarda Vargas Morúa, abogada con maestría en Administración de Negocios. Es tutora en la Escuela de Ciencias de la Administración y miembro de la Comisión Académica de Atención al Matonismo de la Universidad Estatal a Distancia de Costa Rica. Dirección electrónica: evargams@uned.ac.cr 


\section{Introducción}

Mediante el artículo 86 del Reglamento de Evaluación de los Aprendizajes se establecen ocho pasos que deben cumplir los procesos disciplinarios en el ámbito estudiantil. Este reglamento no excluye que cada institución educativa pueda tener su propia normativa interna para aplicar en caso de requerirse acciones correctivas hacia los estudiantes. En el presente trabajo se describe cómo se ha aplicado este reglamento en tres casos concretos en los cuales, las partes afectadas han recurrido a la Sala Constitucional de la Corte Suprema de Justicia y en dicho órgano se han constatado omisiones por parte de los centros educativos durante la tramitación del proceso administrativo.

El estudio de casos concretos analizados por la Sala Constitucional permite contribuir a detectar los errores frecuentes incurridos durante la tramitación de los procesos disciplinarios en los centros educativos.

\section{Metodología}

El trabajo se basa en la revisión documental; específicamente, se recurrió al Centro de Jurisprudencia de la Sala Constitucional de la Corte Suprema de Justicia de Costa Rica (en adelante llamada Sala Constitucional). Este Centro ofrece jurisprudencia, sentencias por tema, consulta de expedientes, estadísticas sobre temas generales a partir del año 2013 en adelante. Como un primer paso, y bajo el tema de bullying o matonismo, se ubicaron diez votos y de ellos se eligieron por conveniencia tres resoluciones relativas al incumplimiento de centros educativos con el principio al debido proceso en materia de correcciones en el ámbito educativo. Se seleccionaron dos casos del año 2014 y uno del año 2015, se eligen por cuanto presentan características homogéneas. Los recurrentes acuden a la Sala Constitucional y esta les da la razón.
Posteriormente, se cotejaron los pasos seguidos por el Centro Educativo, en aplicación del Reglamento de Evaluación de los Aprendizajes y lo ordenado por la Sala Constitucional de la Corte Suprema de Justicia.

Aunque originalmente se indagó bajo el tema de bullying, con los elementos descritos en las resoluciones, no se puede concluir que efectivamente la existencia de este tipo de violencia escolar, aunque sí de violencia escolar en general, tal y como se ampliará más adelante.

\section{Resultados}

Todo costarricense tiene derecho a la educación básica, gratuita y obligatoria. Sin embargo, este derecho debe ejercerse dentro de los límites que las normas establecen y de ahí que las instituciones educativas tienen el deber de abrir procesos disciplinarios, investigar y aplicar medidas correctivas cuando se ha infringido la normativa con el fin de coadyuvar con la formación de los estudiantes.

El Ministerio de Educación Pública, mediante el decreto ejecutivo $\mathrm{N}^{\circ}$ 35355-MEP y publicado en La Gaceta N. ${ }^{\circ} 135$ del 14 de julio del 2009 creó el Reglamento de Evaluación de los aprendizajes, el cual es de observancia tanto para centros educativos públicos como privados. Este reglamento tiene como objetivo establecer la regulación básica del proceso de evaluación de los aprendizajes (artículo primero) y dispone, entre otras temáticas, el procedimiento general en caso de que los estudiantes incurran en faltas disciplinarias.

De tal manera que cuando un centro educativo investigue las conductas de sus estudiantes o deba aplicar medidas para sancionar las acciones $u$ omisiones de estos, debe seguir el procedimiento establecido. Al respecto la Sala Constitucional, en resolución N. ${ }^{\circ}$ 2015013961, indicó:

No obstante, la aplicación de dichas medidas deben seguir un procedimiento previo, destinado a 
descubrir la verdad real de los hechos y a garantizar el derecho de defensa del estudiante... [Para tal efecto] Los centros educativos públicos o privados deben ajustarse al Reglamento de Evaluación de los Aprendizajes. (2015, p.2).

Cualquier centro educativo que no atienda el reglamento, podrá verse compelido a hacerlo o incluso condenado por daños o perjuicios que puedan ocasionarse al omitir su aplicación. Esto podría ocurrir por ejemplo cuando los representantes de los menores acudan a la Sala Constitucional con el fin de hacer valer sus derechos constitucionales como el principio al debido proceso o el derecho de defensa

El Principio al "debido proceso" se encuentra establecido en los artículos 39 y 41 de la Constitución Política de Costa Rica. Bajo este principio se engloban una serie de garantías que se deben respetar en todo proceso. El "derecho de defensa" es otro principio constitucional, establecido en el artículo 39 de la Constitución Política, el 8.1 de la Convención Americana de Derechos Humanos y el 4.5 del Pacto de Derechos Civiles y Políticos e implica la obligación a que "le sea garantizada al ciudadano en todo momento la posibilidad de defenderse en forma amplia y efectiva de los cargos que contra ella hayan sido formulados" (Sala Constitucional de la Corte Suprema de Justicia, 2011, tercer considerando). En otras palabras, es el derecho a defenderse de cualquier acto emanado por el Estado utilizando, para ello, los recursos legales que sean viables para su defensa.

La Procuraduría General de la República (2006) ha indicado respecto a la tutela que ejerce la Sala Constitucional de dichos derechos lo siguiente:

Puede considerarse que el mayor aporte que ha brindado la Sala Constitucional en esta temática... viene a estar constituida por la relevancia que le confiere a los "derechos fundamentales" que deben reconocerse y tutelarse a favor del administra- do que es sujeto de un procedimiento administrativo. Y es con el desarrollo de los conceptos de las garantías constitucionales del "debido proceso" y el "derecho de defensa" que se han perfilado los elementos básicos para que se pueda hablar de un procedimiento administrativo que garantice, efectivamente, la vigencia de esos principios constitucionales. (p. 50).

De tal manera que la Sala Constitucional es el órgano ante el cual se puede solicitar que se verifique si en el desarrollo de un procedimiento administrativo se han respetado los derechos que confiere la Constitución Política a los ciudadanos.

A continuación, se divide la exposición en dos apartados: el proceso disciplinario en la teoría (como debería llevarse a cabo de acuerdo con el reglamento) y el proceso disciplinario en la práctica (falencias en la aplicación de la normativa por parte de los centros educativos), según criterios vertidos por la Sala Constitucional de la Corte Suprema de Justicia.

\section{A. El proceso disciplinario en la teoría}

De conformidad con el artículo 86 del Reglamento General de Evaluación (en adelante REA), se deben cumplir con ocho etapas en el proceso disciplinario. Este proceso es aplicable en todos los niveles, ramas y modalidades del sistema educativo formal.

Los pasos, según el artículo 86 del REA (2009) son los siguientes:

Paso 1: Comunicación de los hechos al docente, técnico o administrativo: Para dar inicio a un proceso disciplinario, se deben comunicar los hechos que puedan constituir una falta al profesional en educación a cargo del estudiante que ha sido protagonista. Cualquier funcionario de la institución, sea el docente, técnico o administrativo debe notificar al guía o al maestro a cargo cuando tengan conocimiento de una falta cometida por un estudiante a su cargo. 
Paso 2: Investigación preliminar: El profesor o profesora guía o maestro (a), en conjunto con el profesional en orientación (si lo hubiere), realizará la respectiva investigación, analizará, verificará si existen o no elementos para la apertura del procedimiento e identificará la supuesta falta cometida y definirá las posibles acciones correctivas, en un plazo que no puede exceder de diez días hábiles.

Paso 3: Comunicación al encargado o encargada del estudiante: En un plazo no mayor de tres días hábiles después de definidas las posibles acciones correctivas a las que se refiere el inciso anterior, el profesional en educación a cargo (llámese el guía), según sea el caso, comunicará por escrito al hogar del menor, las faltas que se le imputan al alumno y las posibles acciones correctivas. Además, le informará de su derecho de acceder al expediente administrativo correspondiente y de la posibilidad de contar con asesoría de un profesional en Derecho para ejercer la defensa del estudiante.

Paso 4: Ejercicio del derecho de defensa por parte del estudiante: El estudiante o sus representantes dispondrán de un término de tres días hábiles, contados a partir de la comunicación del centro educativo (paso 3 anterior), para ejercer su derecho de presentar los argumentos de defensa que estime necesarios, realizar el descargo, alegar lo pertinente y ofrecer las pruebas que juzgue oportunas. Los tres días se contabilizan a partir del día hábil posterior a la notificación. En el mismo escrito en que presente sus argumentos de defensa, es importante que señalen un lugar para recibir notificaciones, el cual puede ser un fax o correo electrónico (de conformidad con la Ley de Notificaciones Judiciales N. ${ }^{\circ} 8687$ ).

Paso 5: Establecimiento de las medidas correctivas: Si en el término de los tres días (a partir de la notificación, según se indicó en el paso 4), el estudiante no presenta pruebas de descargo, el profesional en Educación a cargo del proceso procederá a establecer la medida correctiva que corresponda (de las expresamente señaladas en el reglamento). Para el caso que hubiere descargo dentro del período señalado, se debe proceder a analizar los argumentos y las pruebas que presenten y posteriormente se deberá: a) desestimar la denuncia o b) tomar la decisión de aplicar la medida correctiva.

Paso 6: Resolución final: Los funcionarios del Centro Educativo deberán elaborar una resolución final. En esta se debe informar de las medidas correctivas que se han tomado o si se ha desestimado la denuncia. Esta resolución deberá ser notificada a los representantes del menor (sus padres o encargados) y la copia será enviada al archivo del Comité de Evaluación y al expediente personal del estudiante. El estudiante tiene el derecho de obtener una resolución dentro de un plazo de ocho días hábiles contados a partir del día en que vence el término para presentar el descargo.

Paso 7: Apelación de la resolución ante la $\mathrm{Di}$ rección de la institución: La apelación es un recurso que tiene el estudiante que se encuentre inconforme con la resolución final. Este recurso debe ser presentado ante la institución educativa a más tardar en el tercer día hábil después de que le fue comunicada la acción correctiva. La acción correctiva no puede ejecutarse mientras no venza el periodo indicado para impugnarlo (art. 138 REA) y una vez interpuesto el recurso. Tampoco podrá ejecutarse la corrección, hasta tanto no se resuelva este recurso. La apelación la presentan los representantes del menor y deben hacerlo por escrito y debidamente motivado (con una exposición clara de las razones de su inconformidad con la resolución).

Paso 8: Resolución de la Dirección: El director o la directora conoce y resuelve el recurso interpuesto por los representantes del menor, en un plazo de ocho días máximo posterior a la pre- 
sentación del recurso por parte del menor insatisfecho con la resolución (art. 14.f REA).

\section{B. El Proceso disciplinario en la práctica}

Cuando los representantes del menor consideran que el centro educativo incurrió en una omisión o en un error durante la tramitación del proceso disciplinario pueden, una vez terminado el proceso administrativo, ante la escuela o colegio, recurrir a la Sala Constitucional para ventilar lo acontecido en la vía administrativa y solicitar se estudie si se han visto afectados sus derechos constitucionales.

La Sala Constitucional, de conformidad con la Ley de Jurisdicción Constitucional, es el órgano que tiene por objetivo garantizar la supremacía de las normas y principios constitucionales y del Derecho Internacional vigente, así como los derechos y las libertades fundamentales consagradas en la Constitución o en los instrumentos internacionales de derechos humanos en Costa Rica (art.1).
Por ello, este no es un órgano para dirimir el conflicto entre dos partes con el fin de descubrir la verdad real de los hechos que se denuncien. Por el contrario, sí es el espacio para dilucidar si un órgano público o privado, llámese en este caso un centro educativo, ha respetado o no los principios constitucionales como el debido proceso, el derecho de defensa, el derecho a la educación, la libertad de petición y el derecho a obtener pronta resolución.

B.1 Análisis de casos. Para ejemplificar cómo se llevan en la práctica los procesos disciplinarios, se procederá a comentar tres casos que, una vez concluido el proceso disciplinario, han sido presentados ante la Sala Constitucional.

Caso 1. Recurso de amparo interpuesto por una madre de familia contra un colegio público (expediente: 15-12382-0007-co, resolución 2015013961).

La madre de AR denuncia que su hija es víctima de bullying por parte del joven VG. Recurre a la Sala Constitucional por cuanto el colegio

Tabla 1

Resumen de los hechos

\begin{tabular}{|c|c|c|}
\hline $\begin{array}{l}\text { Pasos según REA aplicados por el } \\
\text { Centro Educativo }\end{array}$ & Hechos descritos en el resultando de la sentencia & Fecha de los hechos \\
\hline & Ofensas e insultos de VG a AR & No indicado \\
\hline & VG insulta a AR. AR da "cachetada" a VG & 22/06/15 \\
\hline Paso 1 & $\begin{array}{l}\text { La madre denuncia en el colegio la existencia de bullying contra su } \\
\text { hija AR. En el Colegio le toman la declaración a AR quien describe que } \\
\text { ante ofensas e insultos constantes de VG procede a defenderse y da } \\
\text { cachetada a VG. } \\
\text { La profesora guía de AR comunica al profesor guía de VG. }\end{array}$ & $23 / 06 / 15$ \\
\hline Paso 2 & $\begin{array}{l}\text { El profesor guía del estudiante VG informa a la profesora guía } \\
\text { de AR, que AR dio cachetada a VG. }\end{array}$ & $20 / 07 / 15$ \\
\hline \multirow[t]{3}{*}{ Paso 5} & Se comunica sanción a AR por agresión física contra VG. & $21 / 07 / 15$ \\
\hline & Madre de AR interpone recurso de apelación ante profesora guía. & 28/07/15 \\
\hline & Profesora guía de AR mantiene sanción impuesta. & 04/08/15 \\
\hline Paso 7 & Madre de AR apela sanción ante el Director. & $10 / 08 / 15$ \\
\hline Paso 8 & Director resuelve y disminuye la sanción a AR. & $14 / 08 / 15$ \\
\hline
\end{tabular}
Nota. Elaboración propia con base en el resultando de la resolución N. ${ }^{\circ}$ 2015-013961de la Sala Constitucional de la Corte Suprema de Justicia (2015). 
no siguió el debido proceso, pues no le permitió ejercer su derecho de defensa y explicar su versión de lo sucedido.

\section{Denuncia relativa a bullying.}

De conformidad con el resultando primero de la sentencia en análisis, en concreto, los hechos acaecidos, según la descripción realizada por la madre de AR son los siguientes: "desde hace un tiempo su hija recibe ofensas e insultos de VG, quien le dice palabras obscenas, hirientes y humillantes... que el 22 de junio... este le gritó "estúpida y zorra apestosa" a lo que esta le respondió que no fuera necio. Sin embargo este la ofendió diciéndole "tierrosa me cago en su madre", por lo que la joven se sintió molesta y le dio una cachetada" (p. 1)

Es menester señalar que la actitud de la víctima, que se describe en dicha sentencia, no es la conducta típica de una víctima de bullying, al contrario, y de conformidad con la doctrina las víctimas suelen ser:

El tipo de víctima más común, las víctimas sumisas o pasivas, suelen compartir las siguientes características: ...

Son prudentes, sensibles, tranquilos, reservados/ introvertidos y tímidos.

Son ansiosos, inseguros, infelices y con baja autoestima... (Serrano, p. 86).

Carozzo, Benites, Zapata y Homa (2012) agregan respecto a las características del bullying:

Podemos afirmar que el bullying tiene las siguientes características: ...Desigualdad de fuerzas entre el agresor y la víctima, porque el agresor abusa de su mayor poder físico o psicológico para intimidar y maltratar a su víctima, a quien causa variadas formas de daño... (p. 14).

Concretamente, el bullying, a diferencia de lo que se describe en los hechos del resultando de la sentencia en estudio:
No son conflictos normales o peleas que se producen entre los estudiantes, sino verdaderos actos de intimidación preconcebidos, amenazas que sistemáticamente, con violencia física o psicológica son repetidamente impuestas a las personas especialmente vulnerables e incapaces de defenderse, lo que los conduce en la mayoría de los casos a una condición de sometimiento, sufrimiento psicológico, aislamiento y marginación (Constantini, 2003, citado por Fante, 2012, p. 29).

Si bien, la madre de la menor alega la existencia de bullying, no es esa la vía para dilucidar si realmente hubo o no matonismo, pero de acuerdo con la caracterización que doctrinalmente se ha realizado, la descripción de la víctima no suele ser la típica de una víctima de matonismo, aunque no se puede descartar tampoco que realmente lo haya sido.

2. Falta respecto a los principios constitucionales.

De la narración de los hechos que se realiza en la resolución, no se observa que la autoridad del centro educativo, haya seguido "un orden" en el procedimiento, tal y como lo señala el REA; es decir, tal y como se observa en la primera columna de la figura 1 anterior, no existe un "paso a paso" al menos cercano, al procedimiento ahí establecido. Si bien es cierto, este tipo de procesos no deben centrar su atención en excesivos formalismos, sí debe respetarse el derecho de defensa de los implicados, escuchándoles y permitiéndoles aportar las pruebas correspondientes para realizar su descargo.

En este caso concreto, siendo una sola causa y los mismos sujetos en estudio, pareciera que se tramitan dos denuncias separadas en lugar de una, lo que dio como consecuencia que no haya claridad respecto a la resolución del centro educativo con respecto a la primera denuncia interpuesta por AR. Además, a la estudiante AR no se le comunica lo manifestado por VG y las posibles acciones correctivas que podría recibir en 
caso de demostrarse los hechos con el fin de que realizara su defensa apropiadamente.

$\mathrm{Al}$ respecto, la Sala en dicha resolución, punto IV, indicó:

si a partir de las declaraciones del estudiante investigado, el Liceo advirtió que la amparada podía haber incurrido en una falta tipificada en el Reglamento de Evaluación de los Aprendizajes, lo correspondiente era comunicar a su encargada la falta supuestamente cometida y las posibles acciones correctivas a imponer (artículo 86 inciso C). No obstante, tal procedimiento no existió. Si bien a la estudiante se le tomó declaratoria, no fue para intimarle sobre la supuesta agresión reclamada por su compañero, sino más bien para que esta confirmara o desmintiera la denuncia planteada por su madre en contra del otro estudiante (Sala Constitucional, 2015, p. 5).

La omisión del centro educativo consistió en no informarle a AR la supuesta agresión que reclamó su compañero VG y ello propició que quien inició como denunciante terminó finalmente acusada de agresión, sancionada y sus- pendida. Al respecto, la Sala Constitucional, punto IV de la sentencia, indicó:

No obstante, sin que conste en autos que se resolviera nada respecto a la denuncia de la recurrente por las supuestas conductas inadecuadas del estudiante indicado, las autoridades del colegio recurrido, cambiaron el sentido de la investigación y resolvieron sancionar a la amparada (Sala Constitucional, 2015, p. 3).

Consecuencia de lo anteriormente descrito, la Sala acoge el recurso, ordena al director y a la profesora guía a evitar incurrir en hechos que dieron origen a la declaratoria sin perjuicio de que vuelvan a iniciar un nuevo procedimiento que respete las garantías del derecho de defensa y debido proceso. Finalmente, se condena al Estado al pago de las costas, daños y perjuicios causados.

Caso 2. Recurso de Amparo contra un centro educativo privado (expediente: 14-009549-0007co, resolución 2014011730).

El segundo caso remite a una situación que se presenta en un colegio en el cual un estudian-

Tabla 2

Resumen de los hechos

\begin{tabular}{llc}
\hline Pasos según REA & \multicolumn{1}{c}{ Hechos descritos en el resultando de la sentencia } & Fechas \\
\hline & A recurre a Servicios de Emergencias debido a & $29 / 04 / 2014$ \\
Paso 1 & Earios golpes que le propinó B en la cabeza. & \\
& El profesor a cargo, durante el suceso, informa a la profesora guía. & $29 / 04 / 2014$ \\
& Se hace apertura de la investigación. & \\
& Se entrevista a B. & $30 / 04 / 2014$ \\
Paso 3 & Los padres de A solicitan investigación de los hechos. & $05 / 05 / 2014$ \\
& Se convoca a entrevista padres de B. & \\
Paso 5 & Se entrevista a menor A. & $06 / 05 / 2014$ \\
& Se presenta el menor A y sus padres, se entrevista a A. & $12 / 05 / 2014$ \\
Paso 7 & Se sanciona a B. & $16 / 05 / 2014$ \\
Paso 8 & Se sanciona a A, por encontrarse también responsable de la falta entre & \\
\hline
\end{tabular}

Nota. Elaboración propia con base en la resolución No. 2014-011730 de la Sala Constitucional de la Corte Suprema de Justicia (2014). 
te recibe una herida en la cabeza provocada por varios golpes que le propinó otro estudiante con una raqueta de ping pong. Los representantes del agredido indican que la directora abrió dos procesos disciplinarios paralelos, uno en contra del alumno agresor y otro en contra del amparado.

En este caso, la Sala determina que se violó el principio del derecho de defensa por parte del centro educativo, por cuanto hubo un problema en la comunicación a los representantes de los menores, respecto a las manifestaciones de la contraparte con el fin de que pudieran presentar sus argumentos de defensa y alegar lo pertinente $\mathrm{u}$ ofrecer pruebas.

Obsérvese que del resumen de los hechos, no se observa el cumplimiento con el paso 4 del reglamento; es decir, con el ejercicio del derecho de defensa por parte del estudiante. En otras palabras, a B se le sanciona por el dicho de A y a A se le sanciona por el dicho de $B$, sin brindársele la oportunidad a cada uno de escuchar la versión de su contraparte y ampliar sus alegatos y sin tener conocimiento de las posibles sanciones en que podrían incurrir.

La Sala, específicamente, indicó respecto al centro educativo lo siguiente:

I) No demostró que previo a la imposición de la sanción hubiere realizado un traslado de cargos explicando las faltas imputadas, las posibles acciones correctivas e informando a los responsables del menor de su derecho de acceder al expediente administrativo y a asesorarse con un abogado.

II) No se constató que se les hubiere otorgado audiencia a los padres de A para presentar por escrito sus alegatos y pruebas de descargo.

En resumen, a los representantes de los menores se les deben comunicar las normas que deben respetar y las sanciones por el incumplimiento.
Consecuencia de las omisiones, la Sala Constitucional, en el considerando sexto de la resolución, ordenó al centro educativo enderezar los procedimientos siguiendo: "en forma estricta los lineamientos que impone para tales efectos el Reglamento de Evaluación de los Aprendizajes" (2014, p. 15)

Adicionalmente, resulta improcedente abrir dos procesos disciplinarios, puesto que la causa que ocasionó el proceso involucra a los mismos sujetos. Entonces,, lo correspondiente sería aperturar un solo proceso disciplinario.

Caso 3. Recurso de Amparo interpuesto contra una escuela pública (expediente 14-15873-0007CO, resolución número 2014-07533).

La Sala indica que si bien la madre de CL fue citada e informada de los hechos por los cuales se investiga al menor, así como también se le comunicó la sanción que se le iba a imponer, no se constató la existencia de una resolución por parte del centro educativo que fundamentara las sanciones por imponer; es decir, el centro educativo elaboró una escueta resolución en la cual solo comunicó la sanción que ordenaba, sin fundamentar los hechos que tuvo por demostrados y los que no, para finalmente concluir explicando la sanción que correspondía consecuencia de los hechos demostrados. Esta omisión puso a la madre de CL en una situación de indefensión.

Si bien, la resolución del centro educativo no es excesivamente formal, sí deben quedar explícitos los hechos que se han tenido por demostrados y la normativa aplicable al caso concreto con el señalamiento de la sanción que corresponde según el reglamento.

$\mathrm{Al}$ igual que en los dos casos anteriores, también existe una omisión, específicamente en el paso 4 del REA; es decir, en el ejercicio del derecho de defensa por parte del estudiante, porque CL es sancionada sin conocer las manifestaciones que JV realizó y, por tanto, no tuvo la opor- 
Tabla 3

Resumen de los hechos

\begin{tabular}{llc}
\hline $\begin{array}{l}\text { Pasos según REA aplicados por el } \\
\text { Centro Educativo }\end{array}$ & \multicolumn{1}{c}{ Hechos descritos en el resultando de la sentencia } & Fecha de los hechos \\
\hline Paso 2 & En clase CL agredió físicamente al compañero JV. & $19 / 08 / 2014$ \\
& JV indica que está cansado que CL le ponga apodos y lo moleste. Se & $22 / 08 / 2014$ \\
& toma declaración a JV, YM y SD. Todos compañeros del Investigado. & $02 / 09 / 2014$ \\
& Se atiende a la madre de CL. Se toma declaración del menor CL. & $04 / 09 / 2014$ \\
Paso 3 & $\begin{array}{l}\text { Se emite primer informe sobre investigación comunicándose posible } \\
\text { sanción. Se da audiencia para realizar descargo y ofrecer pruebas. Se } \\
\text { convoca para el día 10 de setiembre. }\end{array}$ & $10 / 09 / 2014$ \\
& Se entrega resolución final con sanción. Se le informa de el hecho de & \\
poder apelar. & & $17 / 09 / 2014$ \\
Paso 7 & CL presenta recurso de apelación contra la sanción. & $01 / 10 / 2014$ \\
& Director resuelve rechazando la apelación. & $07 / 10 / 2014$ \\
\hline
\end{tabular}

Nota. Elaboración propia con base en el resultando de la resolución N. ${ }^{\circ}$ 2015-013961de la Sala Constitucional de la Corte Suprema de Justicia (2015).

tunidad de responder de manera concreta a lo manifestado por JV.

Esta oportunidad de defensa debe quedar constando en el expediente que debe abrirse por cada proceso administrativo que se abra.

\section{Conclusiones}

1. A través de la aplicación del Reglamento de Evaluación de los Aprendizajes o de los reglamentos internos de cada institución educativa, se pueden ejercer acciones correctivas hacia los estudiantes. Esta aplicación debe hacerse en total apego y respeto a los derechos y los deberes establecidos tanto en la ley como en la Constitución. Sin embargo, en algunos casos, por desconocimiento, se cometen errores en la tramitación de los procesos disciplinarios, de ahí que estudiar resoluciones de la Sala Constitucional de la Corte Suprema de Justicia de Costa Rica permite aprender de las señalizaciones realizadas por este Órgano Jurisdiccional.
2. La violencia escolar está latente en las instituciones educativas de nuestro país. Sin embargo, no todo acto de violencia escolar constituye bullying, como se pretende algunas veces alegar. Este fenómeno reúne ciertas características que deben ser constatadas como la intencionalidad del agresor de causar un daño, la reiteración en el tiempo de las acciones y la desigualdad de fuerzas entre agresor y víctima. Determinar si es o no bullying es una tarea que inicia en el centro educativo y aunque los representantes del menor aleguen la existencia del matonismo, debe demostrarse la relación continuada de violencia entre dos partes y no un disgusto o pelea ocasional.

3. La tarea de los centros educativos consiste en prevenir la violencia escolar. Pero, si esta se llega a dar, debe procederse con base en el Reglamento de Evaluación de los Aprendizajes (REA) y adicionalmente del Reglamento interno de la institución si este existe. 
4. No es la Sala Constitucional el órgano para dirimir un conflicto entre dos partes y descubrir la verdad real de los hechos que se denuncien. Por el contrario, es el espacio para dilucidar si un órgano público o privado, llámese en este caso un centro educativo, ha respetado o no los principios constitucionales como el debido proceso, el derecho a la educación, la libertad de petición y el derecho a obtener pronta resolución. De tal manera, solo se acude a la Sala Constitucional cuando, finiquitado el proceso ante el centro educativo, la parte interesada considera que se han afectado los derechos consagrados en la Constitución.

5. Si bien, los tres centros educativos realizaron una investigación de los hechos denunciados, la omisión consistió en la falta de comunicación a una de las partes, de las manifestaciones realizadas por la contraparte (sea esta igualmente agredida o no). La falta de información impidió que tuvieran la oportunidad de ejercer a plenitud su derecho de defensa, realizar su descargo, presentar sus argumentos y las pruebas que consideraran pertinentes para contrarrestar los argumentos esgrimidos por la contraparte.

6. Todo centro educativo debe aplicar el REA y antes de la imposición de una sanción, debe constatarse que todas las partes fueron informadas de las faltas, las posibles acciones correctivas y se ha informado a los responsables del menor de su derecho de acceder al expediente administrativo y a asesorarse con un abogado; es decir, se debe prestar especial atención en el paso 3 relativo a la comunicación al encargado o encargada del estudiante y el respeto al ejercicio del derecho de defensa (paso 4).

7. En el expediente administrativo debe dejarse constancia del cumplimiento con cada uno de los ocho pasos que se destacan en el REA y con especial esmero en cuanto al paso 3 (de la comunicación de lo dicho por la contraparte) y 4 (de la oportunidad de defenderse de todo lo expuesto en el proceso). Dejar constancia de la comunicación recibida por las partes, respecto a los hechos manifestado por su contraparte, debe ser la constante en el proceso, además de una resolución con una buena fundamentación indicando lo que se ha tenido por demostrado y la sanción procedente de conformidad con el Reglamento.

\section{Referencias}

Asamblea Legislativa (1989) Ley No. 7135, de Jurisdicción Constitucional. En Diario La Gaceta $\mathrm{N}^{\circ} 198,10$ de octubre de 1989. Recuperado de http://www.tse.go.cr/pdf/normativa/leydejusridiccion.pdf.

Asamblea Legislativa (2009) Ley N. ${ }^{\circ}$ 8687, de Notificaciones Judiciales. En Diario La Gaceta $\mathrm{N}^{\circ} 20,29$ de enero de 2009. Recuperado de http://www.pgrweb.go. $\mathrm{cr} / \mathrm{scij} /$ Busqueda/Normativa/Normas/ nrm_texto_completo.aspx?param $1=\mathrm{N}$ RTC\&nValor $1=1 \& n$ Valor $2=64786 \& n$ Valor $3=75313 \&$ param $2=1 \&$ strTipM=TC\&1Resultado $=1 \&$ strSim $=$ simp

Carozzo, J.; Benites, L.; Zapata, L.; Horna, V. (2012). El Bullying no es un juego. Guía para todos. Observatorio sobre Violencia y Convivencia en la Escuela. Lima, Perú.

Fante, C. (2012). Cómo entender y detener el bullying y cyberbullying en la escuela. 112 pregunta y respuestas clave para profesores y padres. Actualización Pedagógica Magisterio: Bogotá,Colombia.

Ministerio de Educación Pública (2009) Reglamento de Evaluación de los Aprendizajes. San José. Recuperado de http://www.pgrweb. go.cr/scij/Busqueda/Normativa/Normas/ nrm_texto_completo.aspx?param1=NRTC\&nValor1 $=1 \&$ nValor $2=65804 \&$ nValor3 $=96343 \&$ strTipM=TC

Petit, L.A. (2011). Estudios sobre el Debido Proceso. Ediciones Paredes: Caracas, Venezuela. 
Sala Constitucional de la Corte Suprema de Justicia (2011). Resolución N. ${ }^{\circ} 2011008872$ de las once horas y cuarenta y seis minutos del uno de julio del dos mil once. Recuperado de http://sitios.poder-judicial.go.cr/salaconstitucional/Constitucion\%20Politica/Sentencias/2011/11-8872.htm

Sala Constitucional de la Corte Suprema de Justicia (2015). Resolución 2015013961 de las 9 horas 5 minutos del 4 de setiembre del 2015.
Sala Constitucional de la Corte Suprema de Justicia (2014). Resolución 2014011730 de las 9 horas 5 minutos del 18 de julio del 2014.

Sala Constitucional de la Corte Suprema de Justicia (2014). Resolución 2014017533 de las 9 horas 40 minutos del 24 de octubre del 2014.

Serrano, A. (2006) Acoso y violencia en la escuela. Cómo detectar, prevenir y resolver el bullying. Barcelona: Editorial Ariel.

Recibido: 9 de mayo de 2016 Aceptado: 6 de setiembre de 2016 